J. Product. \& Dev., 15(3):355- 375 (2010)

\title{
ALLEVIATION OF DROUGHT STRESS EFFECTS AT DIFFERENT GROWTH STAGES OF WHEAT PLANTS BY FOLIAR SPRAY OF SALICYLIC ACID
}

\author{
Seham A. Ibrahim, N. M. El-Sarkassy, G. S.A. Eisa and Nadia H. Kamel
}

Agric. Bot. and Plant Pathology Department, Faculty of Agriculture, Zagazig University, Egypt.

\begin{abstract}
:
Pot experiments were conducted during the two growing winter seasons of 2008/2009 and 2009/2010 under green-house conditions at the Experimental Station, Faculty of Agriculture, Zagazig University, Sharkia Governorate, Egypt to investigate the response of wheat plants (Triticum aestivum L.) cv. Sakha 94 to different levels of foliar application of salicylic acid( SA) at (100, 200 and 400 ppm) on growth criteria, some biochemical analysis i.e. photosynthetic pigments, Photochemical activity, Catalase, superoxide dismutase and Ascorbate Peroxidase activities as well as yield and its components under drought stress conditions.

The data indicated that, all vegetative growth criteria of wheat plants, expressed as plant height (cm), number of tiller/plant, total leaf area/plant $\left(\mathrm{cm}^{2}\right)$, number of leaves/plant, dry weight ( $\left.\mathrm{gm}\right)$ of different plant organs were significantly decreased under drought stress which was imposed at different growth stages. Meanwhile, the foliar application with Salicylic Acid at 200ppm seemed to partially overcome the harmful effects of drought stress on the above mentioned characters of wheat plants.

Yield and its components i.e., number of spikes/plant, number of grains/ spike, number of grains/plant, dry weight of grains /plant ( $g$ ) and 1000-grains weight $(g)$ were significantly decreased by drought stress and the highest values were obtained under control (70\% W.H.C.) and the lowest were obtained under $D S_{2}$ (30\% W.H.C.), although spraying plants with antioxidant, SA at 200 ppm was helpful in improving plant yield but was still lower than the control.

A highly significant decrease in the concentrations of photosynthetic pigments (chl. a, chl. b, chl.a+b and caroteniods),
\end{abstract}

App: DS (Drought Stress), W.H.C. (Water Holding Capacity ), $\mathrm{DS}_{1}$ (50\% of W.H.C.), $\mathrm{DS}_{2}$ (30\% of W.H.C.), SA (Salicylic acid). 
Photochemical activity was observed in fresh wheat leaves in response to drought stress treatments at different growth stages compared with untreated plants. Instead a major response to drought stress, in wheat plants, was the marked increases in the activities of Catalase, superoxide dismutase and Ascorbate Peroxidase in leaves.

Also, the application of salicylic acid( SA) significantly increased in the concentrations of photosynthetic pigments, photochemical activity, and activities of Catalase, superoxide dismutase, Ascorbate Peroxidase in leaves. It can overcome the deleterious effects of drought stress by using antioxidant SA compared with the untreated plants.

Conclusively, it could be recommended the use of SA at 200ppm to partially mitigate the negative effects of drought stress on growth criteria as well as yield and its components of wheat plants.

Key words: Wheat plants (Triticum aestivum L.), Antioxidants, Salicylic acid SA, growth, biochemical analysis, yield, drought stress

\section{INTRODUCTION}

Wheat plant (Triticum aestivum L.) is one of the most important crops in the world. Wheat is considered the first strategic food crop in Egypt. Its grains are a staple human food and straw can be used as a fodder for livestock.

In Egypt, the available amount of irrigation water from River Nile is not only limited but also liable to decrement year after year due to competition of other water usage in the country .Under fixed amount of water (55 milliard $\mathrm{m}^{3} /$ year), water stress may periodically occur during every season in Egyptian crops production.

At the present, the growth of wheat has been seriously influenced by drought in many regions. Drought stress is one of the most serious world-wide problems for agriculture, (El-Tayeb and Naglaa, 2010) since it affects physiological process, and limits plant growth and crop productivity of wheat plant significantly. In Egypt, wheat plants are sometimes exposed to drought stress at different periods of growth. Drought stress produced changes in the ratio of chlorophyll 'a' and 'b' and carotenoids (Farooq et al., 2009). (El-Banna et al., 2002) Growth and primary production of plants are severely reduced by water deficit. Drought is an important limitation to grain yield in many crops (Tambussi, et al., 2000). Drought stress causes oxidative damages in plant cells. Some of compounds which have antioxidative characteristic are Salicylic Acid (SA). This compound can decrease drought effects in plants under stress (Baghizadeh et al, 2009). It seems that salicylic and ascorbic acid can considerably alleviate oxidative damage that occurred under drought stress 
condition. Therefore, it could be concluded that salicylic acid in the concentration $1 \mathrm{mM}$ have in mitigation of stress caused by drought stress.

Salicylic acid (SA) acts as an important signal molecule modulating plant responses to stress, (Krantev et al., 2006). it has been responsible for inducing abiotic stress tolerance (El Tayeb and Naglaa, 2010) and considerable interests have been focused on SA due to its ability to induce a protective effect on plants under stress such as drought tolerance in wheat plants (Singh and Usha, 2003 and Gunes et al., 2007).

Salicylic acid is an endogenous growth regulator of phenolic nature, which participates in the regulation of physiological processes in plant (Joseph et.al, 2010) such as stomatal closure, nutrient uptake, chlorophyll synthesis, and protein synthesis, inhibition of ethylene biosynthesis, transpiration and photosynthesis. (Khan et al., 2003 and Shakirova, et al, 2003).Several studies have shown that salicylic acid is an essential component of the plant resistance to pathogens and participates in the plant response to adverse environmental conditions. Salicylic acid used to increase plants tolerance against the adverse effects of biotic and abiotic stresses. (Shakirova, et al., 2003; Bosch, et al., 2007 and Chen et al., 2007). Ameliorative effect of SA on growth of crop plants under abiotic stress conditions may have been due to its role in photosynthesis and growth (Khan et al., 2003 and Arfan et al., 2007).

Therefore, the present investigation was undertaken to alleviate the harmful effect of drought stress on growth, yield and biochemical constituents of wheat plants by applying antioxidant SA. Studying the responses of wheat plants (Triticum aestivum L.) cv. Sakha 94 to foliar application of antioxidant i.e., salicylic acid( SA) at (100, 200 and $400 \mathrm{ppm})$ on growth criteria, some biochemical analysis i.e. photosynthetic pigments, Photochemical activity, Catalase , superoxide dismutase and Ascorbate Peroxidase activities, as well as, yield and its components grown under drought stress conditions.

\section{MATERIALS AND METHODS}

Pot experiments were carried out during the two successive seasons of 2008/ 2009 - 2009 / 2010, under green-house conditions at the Experimental Station, Faculty of Agriculture, Zagazig University, Sharkia Governorate, Egypt, to study the effect of foliar application of Salicylic (SA),on some morphological criteria, yield and its component, as well as, photosynthetic pigments, Photochemical activity, superoxide dismutase and Ascorbate Peroxidase activities in the leaves of wheat plants (Triticum aestivum L.) $c v$. Sakha 94 grown under drought stress conditions.

Wheat grains (Triticum aestivum L.) cv. Sakha 94 was obtained from Wheat Research Section, Crop Research Institute, Agriculture Research Center, 
Giza. Grains were sown on the $26^{\text {th }}$ November in both season in plastic pots $33 \mathrm{~cm}$ inner diameter and $25 \mathrm{~cm}$ in depth. Each pot contained $10 \mathrm{~kg}$ of air dried clay soil.

The treatments were three levels of drought stress : control (70\%), $\mathrm{DS}_{1}$ $(50 \%)$, and $\mathrm{DS}_{2}(30 \%)$ of water holding capacity (W.H.C), respectively and different levels of salicylic acid (SA) 0.00, 100, 200, 400 ppm concentration were applied as a foliar spray. Fifteen grains/pot were sowing at equal distances and depth. After two weeks from sowing, seedlings were thinned to eight seedlings /pot.

The recommended agricultural practices of growing wheat were applied and Phosphorus fertilizer in the form of Calcium super phosphate $\left(15.5 \% \mathrm{P}_{2} \mathrm{O}_{5}\right)$ was mixed with the soil before planting at the rate of $1.8 \mathrm{gm} \mathrm{P}_{2} \mathrm{O}_{5} /$ pot. While, Potassium and nitrogen fertilizers in the form of Potassium sulphate (48\% $\mathrm{K} 2 \mathrm{O})$ and Urea $(46 \% \mathrm{~N})$ were added individually with water irrigation after thinning at the rate of $1.3 \mathrm{gm} \mathrm{K}_{2} \mathrm{O} /$ pot and $1.3 \mathrm{gm} \mathrm{N} /$ pot.

After germination, every pot was weighted daily and the needed amount of irrigation water was added.

Wheat plants were foliar sprayed with salicylic acid (SA) at the concentration of $0.00,100,200$ and 400ppm, respectively. In both seasons, foliar applications of salicylic acid was carried out three times using hand atomizer and wetting agent after 25, 45 and 65 days from sowing. Control plants were sprayed with distilled water and the volume of the spraying solution was maintained just to cover completely the plant foliage till drip. The experiment comprised 180 pots which represented 12 treatments with 15 replications using complete randomization design.

Three samples were taken throughout the experimental period at 35 days after sowing ( tillering stage), 55 days after sowing (stem elongation stage) and 75 days after sowing (heading emergence stage).

The following data were recorded:

I. Plant Growth characters: The following data were recorded: plant height $(\mathrm{cm})$, number of tiller/plant, number of leaves/plant, total leaf area/plant $\left(\mathrm{cm}^{2}\right)$ and dry weight/plant (gm) of shoot, and root systems. Plant samples were dried in an electric oven with drift fan at $70^{\circ} \mathrm{C}$ for $48 \mathrm{hr}$. till constant dry weight. All morphological characters were recorded at the three growth stages.

\section{Physiological and biochemical analysis:}

The same above mentioned samples were used to estimate the following chemical analysis:

a- Photosynthetic pigments were determined as described by Wettestein (1957), then calculated as $\mathrm{mg} / \mathrm{g}$ fresh weight. 
b- Photochemical activity in wheat plant in fresh leaves were determined according to Jagendorf (1956) and modified by Avron (1960).

c- Enzymatic antioxidant activity was estimated in the third sample of the second season only.

Enzyme extraction: The extraction was carried out according to the method reported by Vitoria et al. (2001).

1. Catalase specific activity: Catalase was assayed spectro-photochemically according to Chance and Maehly (1955).

2. Ascorbate peroxidase (As-POD) specific activity: Ascorbate peroxidase (As-POD) was assayed spectro-photo-chemically according to Fielding (1978).

3. Super oxide dismutase (SOD) activity: Fresh leaf samples were collected in an ice-bucket and brought to the laboratory. Leaves were then washed with distilled water and surface moisture was wiped out. Leaf samples $(0.5 \mathrm{~g})$ were homogenized in ice cold $0.1 \mathrm{M}$ phosphate buffer $(\mathrm{pH} 7.5)$ containing $0.5 \mathrm{mM}$ EDTA with pre-chilled pestle and mortar. The homogenate was transferred to centrifuge tubes and was centrifuged at $4{ }^{\circ} \mathrm{C}$ in Beckman refrigerated centrifuge for $15 \mathrm{~min}$ at $15000 \times \mathrm{g}$. The supernatant was transferred to $30 \mathrm{ml}$ tubes and referred to enzyme extract.

SOD activity was estimated by recording the decrease in absorbance of superoxide-nitro blue tetrazolium complex by the enzyme ( Sairam et al., 2002).

\section{Yield and its Components:}

At harvest stage, the mean values of yield and its components, i.e., number of spikes/plant, number of grains/ spike, number of grains/plant, dry weight of grains /plant (g) and1000-grain weight (g) was determined.

\section{Statistical analysis:}

All data were subjected to statistical analysis using complete randomization design according to Snedecor and Cochran (1990). Means separation was done by L.S.D. at 0.05 and 0.01 levels of probability.

\section{RESULTS AND DISCUSSION}

\section{Plant Growth characters:}

Data presented in Tables (1, 2 and 3) show the effect of foliar application of salicylic acid on growth of wheat plants grown under different levels of drought stress. It's clear from the data that, both salicylic acid treatment and drought stress levels had significant different effects on plant height $(\mathrm{cm})$, number of tillers/plant, number of leaves/plant, total leaf area/plant during different stages of growth. The highest value was recorded with $70 \%$ of 
W.H.C.(Control) and the lowest one was obtained with DS2 (30\% of W.H.C.) at different growth stages.

In this connection, Ute Schuppler et al., (1998), reported that wheat (Triticum aestivum L.) seedlings subjected to a mild water stress (water potential of $0.3 \mathrm{MPa}$ ), the leaf-elongation rate was reduced by one-half and the mitotic activity of mesophyll cells was reduced to $42 \%$ of well-watered control. There was also a reduction in the length of the zone of mesophyll cell division to within $4 \mathrm{~mm}$ from the base compared with $8 \mathrm{~mm}$ in control leaves. Nakamura et al.(2003) and Dhanda and Sethi (2003)

It is interest to mention that foliar application of salicylic at 100,200 ppm exhibited the highest values of plant height $(\mathrm{cm})$, number of tillers, and number of leaves/plant, total leaf area/plant and dry weight of roots and shoots for wheat plants as compared to untreated plant with SA. These results hold true at different growth stages. In all cases, the increments in growth parameters were often highly significant in comparison with untreated ones.

Salicylic acid at $200 \mathrm{ppm}$ was the most effective treatment in increasing growth parameters of wheat plants, whereas, increasing salicylic concentration up to $400 \mathrm{ppm}$ significantly decreased them at different stages of growth. In this respect, many investigators found that low concentrations of salicylic acid enhanced growth of wheat plants (Shakirova et al., 2003; Iqbal and Ashraf, 2006),

Salicylic acid (SA) is an important signal molecule modulating plant responses to stress. Recently, it has been reported that, it induces multiple stress tolerance in plants including drought (El Tayeb and Naglaa 2010).

Concerning the effect of antioxidant treatments by spraying wheat plants with salicylic acid in the rate of $200 \mathrm{ppm}$ on plant height $(\mathrm{cm})$, tiller numbers, number of green leaves/plant, total leaf area/plant. It is likely to mention that, SA partially overcame the harmful effect of drought stress,(Amin et.al., (2008).

SA improved the wheat plant growth under drought stress of both seasons. These results are in agreement with those of El-Tayeb (2005) on barley plants and Arfan et al. (2007) on wheat plants . They reported that exogenous foliar application of SA ameliorated the adverse effects of salt stress on growth by enhancing protein and nucleic acids and hormonal balance. Also, Singh \& Usha (2003) found that, foliar application of SA caused enhancement in biological yield of wheat under water stress compared with untreated SA plants but these results were less than control plants. In the case of salicylic acid role in growth parameters, it was reported that salicylic acid set the expansion, division and cell death (Zhang et al.,2002). 
In conclusion, the adverse effects of drought stress on the growth criteria of wheat plants c.v. Sakha 94 can be partially mitigated by foliar spray of salicylic acid (SA) at 200ppm.

\section{Physiological and biochemical analysis: a- Photosynthetic pigments:}

The lowest value of Photosynthetic pigments under drought stress levels were recorded under $\mathrm{DS}_{3} 30 \%$ W.H.C., through the three samples.

Farooq, et al., (2009) and Reddy, et al., (2004) noticed that, drought stress decreased and produced changes in the ratio of chlorophyll ' $a$ ' and ' $b$ ' and carotenoids under drought stress condition.

The limitation of photosynthesis under drought through metabolic impairment is more complex phenomenon than stomatal limitation and mainly it is through reduced photosynthetic pigment contents

Abdul Jaleel, et al., (2009) recorded that, Water deficit is one of the major abiotic stresses, which adversely affects crop growth and yield. These changes are mainly related to altered metabolic functions, one of those is either loss of or reduced synthesis of photosynthetic pigments.

Data in Tables (4 and 5) show that applied $\mathrm{Sa}$ enhanced photosynthetic pigments in the leaves of wheat plants under drought stress condition compared with untreated SA plants but these increases were still under control plants (70\%W.H.C.)

Ameliorative effect of SA on growth of crop plants under abiotic stress conditions may have been due to its role in photosynthesis which reflect on growth (Khan et al., 2003). Also, (Singh \& Usha, 2003) found that, SA has a role in abiotic stress tolerance such as drought stress in wheat.

Moreover, drought stress alone causes decreasing photosynthetic pigments as compared with control plants, the decrease of these pigments content in wheat plant that grown under drought stress conditions are improved by salicylic acid treatment.

\section{b- Photochemical activity:}

Drought stress treatments decreased significantly the values of photochemical activity of wheat homogenate leaves. This reduction was pronounced at different growth stages in two seasons.

The severe drought stress treatment $\left(\mathrm{DS}_{2}\right)$ abolished the photochemical activity of wheat homogenate leaves. Increasing drought stress $\left(\mathrm{DS}_{2}\right)$ caused a reduction in photochemical activity at different growth stages when compared with control plants.

These results are agreement with those obtained by Reddy, et al., (2004) who found that drought stress progressively decreases photosynthetic 
pigments synthesis and $\mathrm{CO}_{2}$ assimilation rates due to the reduction of stomatal conductance. Drought stress also induces reduction in the contents and activities of photosynthetic carbon reduction cycle enzymes, including the key enzyme, ribulose- 1,5-bisphosphate carboxylase/oxygenase.

SA showed significantly increment in photochemical activity of wheat leaf tissue homogenates at different growth stages. According to Joseph et al. (2010) exogenous application of salicylic acid proved to enhancing the photosynthesis, growth and various other physiological and biochemical characteristics of plants.

It could be mention that applied SA could partially alleviate the harmful effect of drought stress on photochemical activity in wheat plants grown under drought stress condition.

\section{c- Enzymatic antioxidant activity:}

Superoxide dismutase (SOD), ascorbate peroxidase (APX), Catalase (CAT)

The data presented in Table (7) showed the changes of SOD, CAT and APX activities in the leaves of wheat plants as affected by drought stress and foliar spray with salicylic acid.

It is evident that, the severe drought stress treatments and/or its combination with SA increased significantly the values of SOD, CAT and APX activities in the leaves of wheat plants. This increasing was pronounced in the third sample in 2009 / 2010 season.

The obtained results concerning the effect of drought stress on SOD, CAT and APX activities of wheat homogenate leaves are agreement with those obtained by Foyer and Halliwell (1976) who reported that investigated enzymes activities clearly increased the activities of all the enzymes of ascorbate-glutathione cycle, signifying a potential role of these enzymes in providing antioxidative defense under drought stress conditions. Ascorbate peroxidase (APX) prevents the accumulation of excess $\mathrm{H}_{2} \mathrm{O}_{2}$ in cells via ascorbate-glutathione pathway.

Sharma and Dubey (2005) the activities of total superoxide dismutases (SODs), as well as, ascorbate peroxidase (APX) showed consistent increases with increasing levels of drought stress, however catalase activity declined.

Regarding the effect of foliar application with salicylic acid on SOD, CAT and APX activities of wheat leaf tissue homogenate in third sample is shown in the same Table 7.

The results of spraying plants with SA effects on SOD, CAT and APX activities in the leaves of wheat plants showed significant increases in SOD, CAT and APX activities of wheat leaf tissue homogenates in the third 
Table 7 : Effects of foliar application with Salicylic acid (SA) on enzymatic antioxidant activities (Superoxide dismutase (SOD), Ascorbate Peroxidase (As-POD) and Catalase (CAT) of wheat plants cv. Sakha 94 grown under different levels of drought stress at 75 days after sowing (Sample 3) in 2009/2010 season.

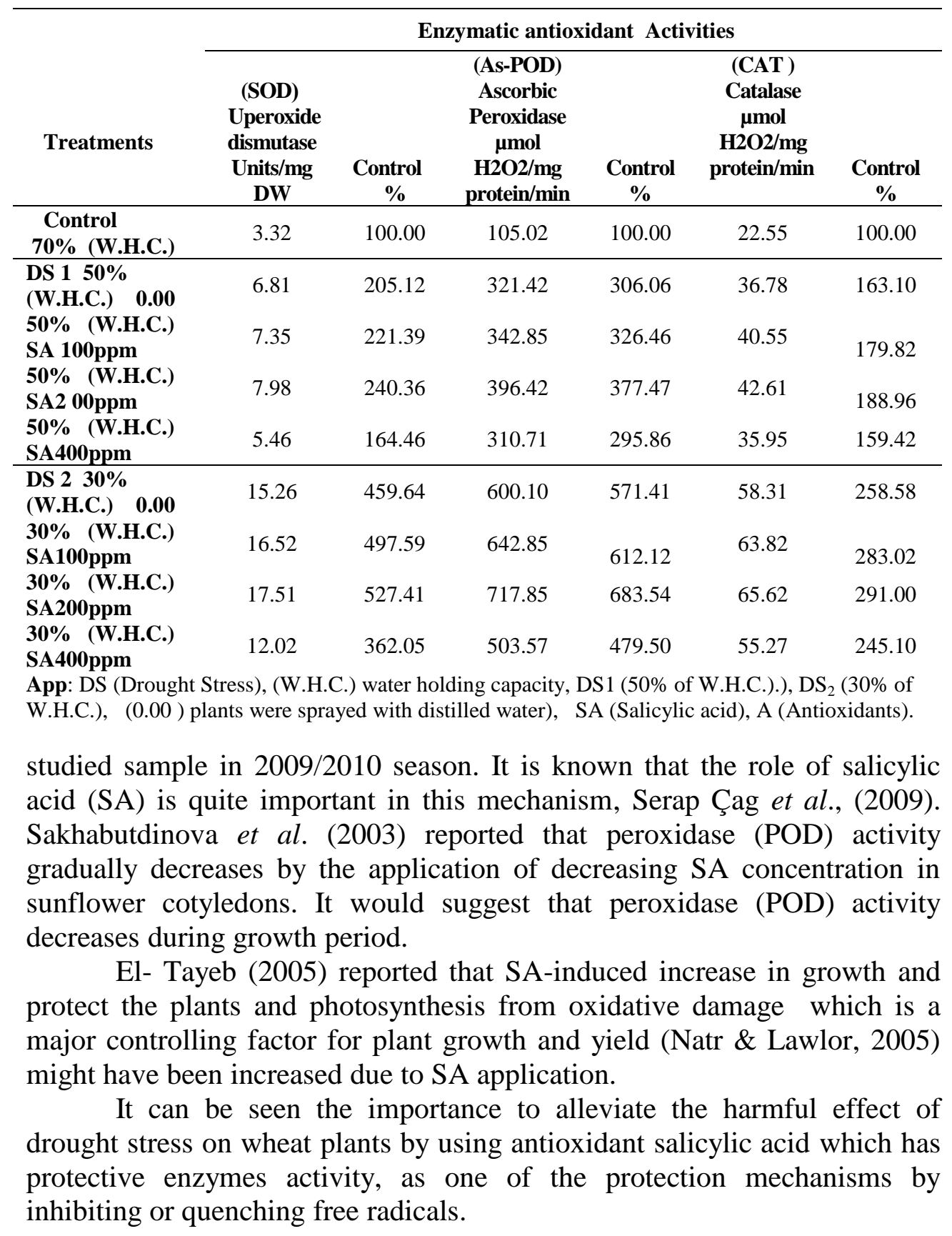




\section{Yield and its components:}

The data in Table (8) noticed that drought stress $\mathrm{DS}_{1}$ and $\mathrm{DS}_{2}$ showed a highly significant reduction in yield and its components like as number of spikes/plant, number of grains/spike, number of grains/plant, dry weight (D. Wt.) of grains/plant and consequently weight of 1000 grains.

The moderate drought stress treatment ( $\mathrm{DS}_{1} 50 \%$ W.H.C.) reduced number of spikes/plant, number of grains/spike, number of grains/plant ,D. Wt. of grains/plant and 1000 grain weight comparable to the control plants in the first and second seasons, respectively.

The severe drought stress treatment ( $\mathrm{DS}_{2} 30 \%$ W.H.C.) was more effective than moderate ( $\mathrm{DS}_{1} 50 \%$ W.H.C.) in decreasing yield and its components when compared to the control plants in the $1^{\text {st }}$ and $2^{\text {nd }}$ seasons, respectively.

Water stress affected many physiological process, growth and yield of wheat plant. It decreased 1000 grain weight and grain yield (El-Banna et al., 2002).

Amin et al. (2008) reported that, an enhancement effect on growth characters and yield in wheat plants was obtained by 100 or $200 \mathrm{mg} \mathrm{L}^{-1}$ of salicylic acid. Moreover, the same preceding underwent a reverse pattern of change using the higher concentrations of salicylic acid $\left(400 \mathrm{mg} \mathrm{L}^{-1}\right)$.

In conclusion, the results showed that wheat yield and its components was highly reduced under drought stress, although spraying plants with antioxidant especially salicylic acid at 200ppm was helpful in improving plant yield but was still lower than the control.

\section{REFERENCES}

Abdul Jaleel, C. ; P. Manivannan, Abdul Wahid; M. Farooq ; J. AL Juburi, R. Somasundaram and R. Panneerselvam (2009): Drought Stress in Plants: A Review on Morphological Characteristics and Pigments Composition. Int. J. Agric. Biol., 11: 100-105.

Amin A.A. ; El-Sh.M. Rashad and Fatma, A.E. Gharib (2008): Changes in Morphological, Physiological and Reproductive Characters of Wheat Plants as Affected by Foliar Application with Salicylic Acid and Ascorbic Acid. Australian Journal of Basic and Applied Sciences, 2 (2): 252-261

Arfan, M. ; H.R. Athar and M. Ashraf (2007): Does exogenous application of salicylic acid through the rooting medium modulate growth and photosynthetic capacity in two differently adapted spring wheat cultivars under salt stress?. J. Plant Physiol., 6 (4): 685-694. 
Avron, M.(1960): Photophosphorylation by swisschard chloroplasts. Biochim. Biophys. Acta., 40:257-272.

Baghizadeh A. ; M., Ghorbanli ; R. M., Haj Mohammad and H.,Mozafari (2009): Evaluation of Interaction Effect of Drought Stress with Ascorbate and Salicylic Acid on Some of Physiological and Biochemical Parameters in Okra (Hibiscus esculentus L.) . Res. J. of Biol. Sci., 4 ( 4 ): 380-387.

Bosch, S.M. ; J. Peñuelas and J. Llusià, (2007): A deficiency in salicylic acid alters isoprenoid accumulation in water-stressed NahG transgenic Arabidopsis plants . Plant Science, 172 Issue, 4: 756-762.

Chance, B. and A. C. Maehly, (1955): Assay of catalase and peroxidase. Methods in Enzymology. , 2: 764-775.

Chen, J. ; C. Zhu; L. LI; Z. Sun and X. Pan, (2007): Effects of exogenous salicylic acid on growth and $\mathrm{H} 2 \mathrm{O} 2$-metabolizing enzymes in rice seedlings under lead stress. J. Environ. Sci., 19, Issue, 1: 44-49.

Dhanda, S. S. and G. S. Sethi (2003): Variability and drought resistance in wheat at different stages of plant growth. National J. of plant Improvement, 5 (1): 61 - 64.

El-Banna, M. N.; M. A. A. Nassar; M. A. Moustafa and S. H. Abd-Allah (2002): Evaluation of some wheat genotypes under drought conditions in Nubaria region. Jr. of advances in Agric. Res., 7 (2): 349-366.

EI -Tayeb, M.A. (2005): Response of barley grains to the interactive effect of salinity and salicylic acid. Plant Growth Regul., 45:215-224.

El -Tayeb M.A. and Naglaa L. Ahmed (2010): Response of Wheat Cultivars to Drought and Salicylic Acid. American-Eurasian Journal of Agronomy, 3 (1): 01-07.

Farooq, M., A. Wahid and N. Kobayashi, D. Fujita and S.M.A. Basra (2009): Plant drought stress: effects, mechanisms and management. Agron. Sustain. Dev., 29: 185-212.

Fielding, J. L. hall, (1978): a biochemical and cytochemical study of peroxidase activity in root of Pisum sativum. Journal of Experimental Botany, 29: 969-981.

Foyer, C.H., and B. Halliwell (1976): The presence of glutathione and glutathione reductase in chloroplasts: a proposed role in ascorbic acid metabolism. Planta, 133: 21-25.

Gunes, A., A. Inala, M. Alpaslana, F. Eraslana, Esra G. Bagci and N. Ciceka (2007): Salicylic acid induced changes on some physiological parameters symptomatic for oxidative stress and mineral nutrition in maize (Zea mays L.) grown under salinity. Journal of Plant Physiology, Volume 164, Issue 6, 4 June 2007, Pages 728-736. 
Iqbal, M. and M. Ashraf, (2006): Wheat seed priming in relation to salt tolerance, growth, yield and level of free salicylic acid and polyamines. Ann. Bot. Fennici., 43(4): 250-259.

Jagendorf, A.T. (1956): Oxidation and reduction of pyridine nucleotides by purified chloroplasts .Arch.Biochem. Biophys., 62:141-150.

Joseph,B. ,D. Jini and S. Sujatha (2010): Insight into the role of Exogenous Salicylic Acid on Plants Grown under Salt Environment. Asian Journal of Crop Science, 2(4): 226-235.

Khan, W., B. Prithiviraj and D.L. Smith, (2003): Photosynthetic response of corn and soybean to foliar application of salicylates. J. Plant Physiol., 160: 485 .

Krantev, A., R. Yordanova and L. Popova. (2006): Salicylic acid decreases Cd toxicity maize plants. General and Applied Plant Physiology, Special Issue, 45-52.

Nakamura, E., T. Ookawa, K. Ishihara and T. Hirasawa (2003): Effects of soil moisture depletion for one month before flowering on dry matter production and ecophysiological characteristics of wheat plants in wet soil during grain filling. Plant Production Sci. , 6 (3): $195-205$.

Natr L, and D.W. Lawlor. 2005. Photosynthetic plant productivity. In Photosynthesis Handbook, (2nd Ed). M. Pessarakli. C.R.C. Press, New York, USA. p. 501-524.

Reddy, A.R., K.V. Chaitanya and M. Vivekanandan, (2004): Drought induced responses of photosynthesis and antioxidant metabolism in higher plants. Journal of Plant Physiology, V.161, P.1189 -1202.

Sairam, R.K., K. Veerabhadra Rao and G. C. Srivastava (2002): Differential response of wheat genotypes to long term salinity stress in relation to oxidative stress, antioxidant activity and osmolyte concentration. Plant Science, 163, (5): 1037-1046.

Serap Çag, GÜl Cevahir-ÖZ, Mine Sarsag and Nihal GÖren-Saglam (2009): Effect of salicylic acid on pigment, protein content and peroxidase activity in excised sunflower cotyledons .Pak. J. Bot., 41(5): 2297-2303, 2009.

Sakhabutdinova, A.R., D.R. Fatkhutdinova, M.V. Bezrukova and F.M. Shakirova (2003): Salicylic acid prevents the damaging action of stress factors on wheat plants. Bulgarian Journal of Plant Physiology, Special Issue, 314-319.

Shakirova, M.F., A.R. Sakhabutdinova, M.V. Bezrukova, R.A. Fatkhutdinova and D.R. Fatkhutdinova (2003): Changes in the hormonal status of wheat seedlings induced by salicylic acid and salinity. Plant Science, 164 Issue, 3: 317-322. 
Sharma, P. and R.S. Dubey (2005): Drought induces oxidative stress and enhances the activities of antioxidant enzymes in growing rice seedlings. Plant Growth Regulation , 46:209-221.

Singh, B. and K. Usha (2003): Salicylic acid induced physiological and biochemical changes in wheat seedlings under water stress. Plant Growth Regul., 39:137-141.

Snedecor, G.W. and W.G. Cochran, (1990). "Statistical Methods." 8th Ed. Iowa state Univ. Press, Ames Iowa, U.S.A.

Tambussi EA, C.G. Bartoli, J. Beltrano, J.J. Guiamet, J.L. Araus (2000): Oxidative damage to thylakoid proteins in water-stressed leaves of wheat (Triticum aestivum L.). Physiologia Plantarum, 108: 398 - 404.

Ute Schuppler, Ping-Hua He, Peter C.L. John, and Rana Munns (1998): Effect of Water Stress on Cell Division and Cdc2-Like Cell Cycle Kinase Activity in Wheat Leaves. Plant Physiol., 117: 667-678.

Vitoria, A. P., P. J. Lea, and R. A. Azevado, (2001): antioxidant enzymes responses to cadmium in radish tissues. Phytochemistry. 57: 701-710

Wettestein, D. (1957). Chlorophyll-Lethal undder submink roskopische formivechoel der plastiden. Exp. Cell. Res., 12: 427 - 433.

Zhang, W., C. Curtin, M. Kikuchi and C. Franco, 2002. Integration of jasmonic acid and light. Irradiation for enhancement of anthocyanin biosynthesis in Vitis infer suspension .Cultures. Plant Sc., 162:459-468.

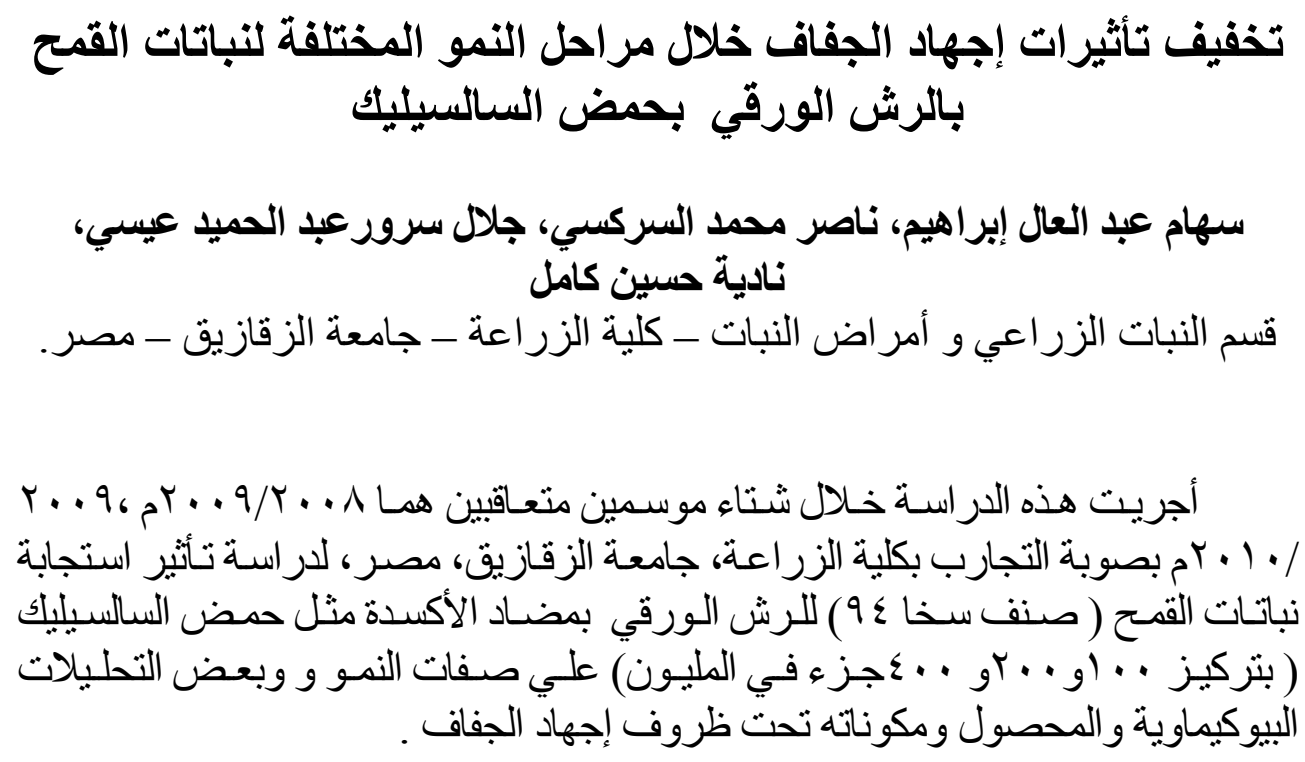


أوضحت صفات النمو الممثلة في ارتفاع النبات(سم) و عدد الاشطاء /نبات و عدد أنداء

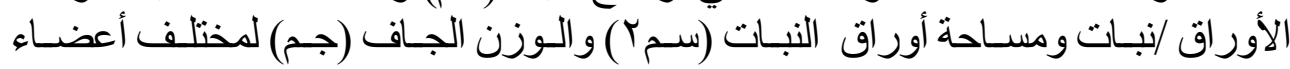

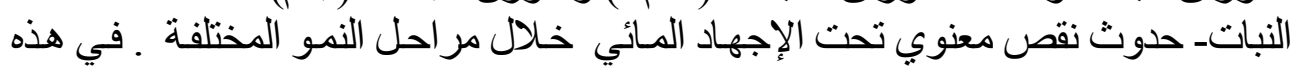

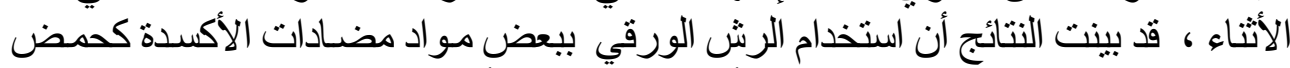

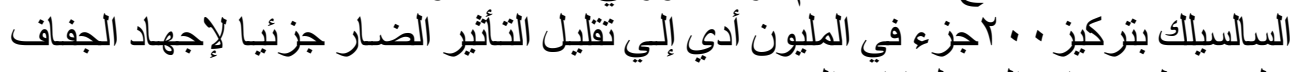

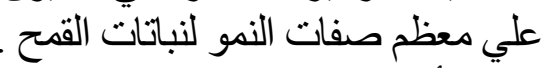
أظهرت نتائج التحليل الكيماوي لأور اق القمح حدوث نقص ملت معنوي في تركيزات كل

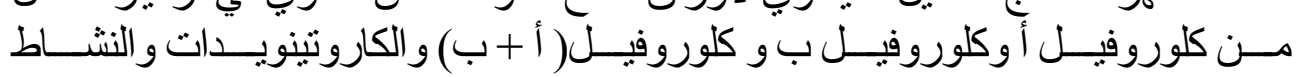

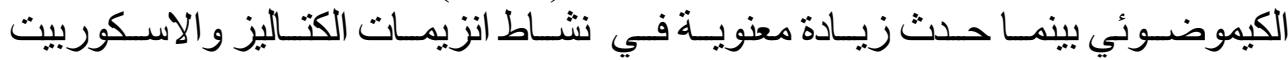

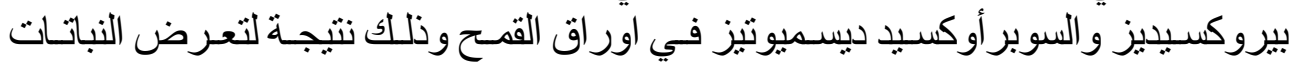

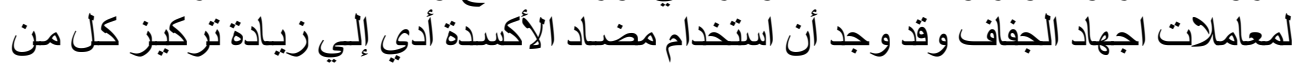

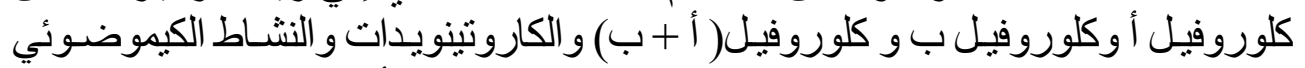

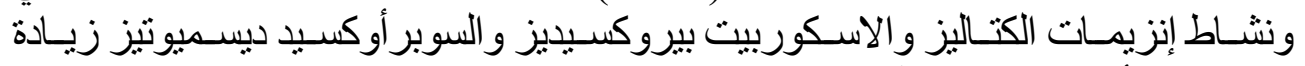

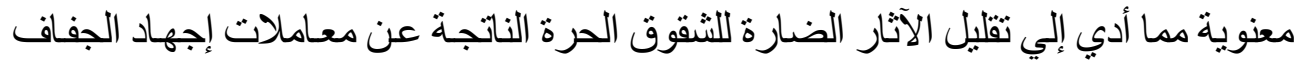

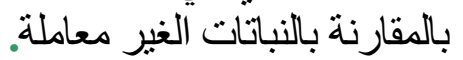

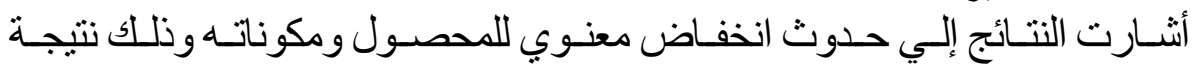

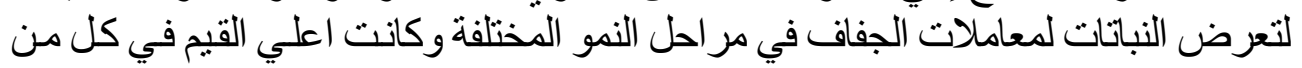

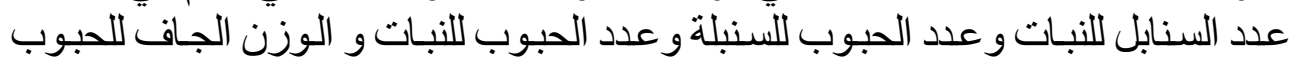

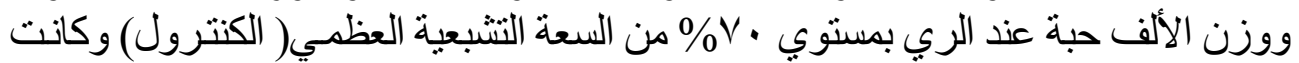

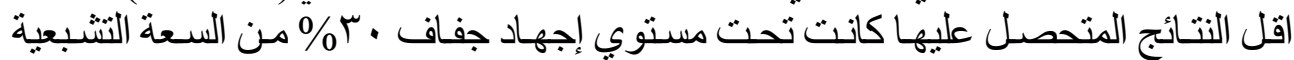

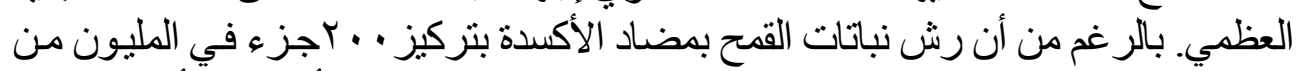

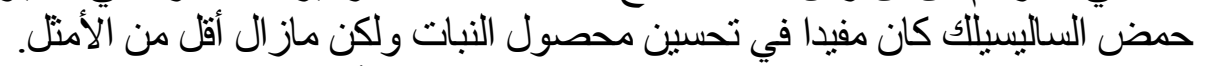

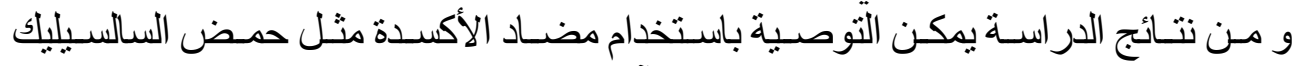

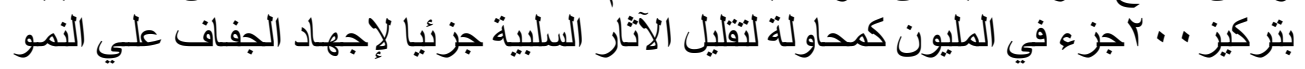

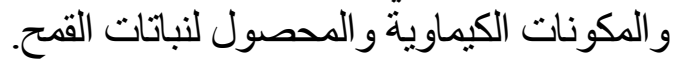

